\title{
Volición conservadora en las acciones violentas de La ciudad y los perros'
}

\author{
Conservative Volition in the Violent Actions of The Time of the Hero
}

\author{
JESÚS MIGUEL DELGADO DEL AGUILA \\ Universidad Nacional Mayor de San Marcos
}

Perú

tarmangani2o88@outlook.com

(Recibido: IO-O6-202O; aceptado: 2I-O5-2O2I)

Resumen. Este artículo se adscribe a la percepción conservadora que trabaja Mario Vargas Llosa para la construcción discursiva de La ciudad y los perros. Esa ideología política caracterizada por su autonomía e imparcialidad permitirá reconocer el propósito del autor al abordar el talante de la violencia en el desempeño de los personajes. Para su fluctuación efectiva, este estudio comprenderá tres tratamientos neurálgicos y conexos en torno a esta obra literaria: la contextualización extratextual, la epistemología de la violencia y el análisis narratológico desde los actantes concomitantes. Esta taxonomía convencional que se formula será de utilidad para justificar en qué medida la violencia adquiere una valía medular para el desarrollo humano.

Palabras clave: conservadurismo; narratología; violencia; taxonomía; Boom latinoamericano.
Abstract. This paper is ascribed to the conservative perception that Mario Vargas Llosa works for the discursive construction of The Time of the Hero. This political ideology characterized by its autonomy and impartiality will allow us to recognize the author's purpose when addressing the mood of violence in the performance of the characters. For its effective fluctuation, this study will include three neuralgic and related treatments around this literary work: the extratextual contextualization, the epistemology of violence and the narratological analysis from the concomitant actants. This conventional taxonomy that is formulated will be useful to justify the extent to which violence acquires a core value for human development.

Keywords: conservatism; narratology; violence; taxonomy; Latin American Boom.

\footnotetext{
I Para citar este artículo: Delgado del Aguila, Jesús Miguel (202I). Volición conservadora en las acciones violentas de La ciudady los perros. Alabe 24 . [www.revistaalabe.com]

DOI: IO.I5645/Alabe2O2I.24.IO
} 


\section{Introducción}

En el presente trabajo, se apreciará cómo se instala el paradigma de conservadurismo en el tratamiento de la violencia que propicia Mario Vargas Llosa en La ciudady los perros. Esa afiliación política será de provecho para comprender la intención del autor de no intervenir en el desarrollo de las acciones de los personajes. La volición de esa derelicción ideológica es originar una construcción panorámica y crítica en el lector. Para demostrar ese objetivo, esta investigación será sometida a un abordaje desde el contexto, la violencia y la narratología.

Para empezar, es necesario hacer una precisión con respecto a la posición conservadora del autor frente al tópico de la violencia. Este tema de por sí se incluye al igual que otros malestares culturales que se corroboran en América Latina del siglo XX. Sin embargo, aquello que se vincula con las prácticas de agresión será de utilidad para explicar el enfoque que se hará en una primera sección. Para fundamentar el contexto, retomaré el Gobierno dictatorial de Manuel Odría, que se caracterizó por la ausencia de libertad de expresión y su intento de querer instaurar el concepto de progreso por medio de la disciplina castrense. Ese método de instrucción no generaba una atmósfera de aceptación en la ciudadanía, por lo que se producirán otros lineamientos sociopolíticos que se encargarán de erradicar esa epifanía. Asimismo, será meritorio especificar que en ese periodo surgió un fenómeno editorial denominado el boom, el cual se distinguió por su pretensión de innovar a través de la plasmación fidedigna de todo lo que acontecía en la sociedad. Esa percepción de por sí ya remontaba el pensamiento conservador del autor, porque lo que interesa más es la representación de los hechos sin alterar absolutamente nada. Para terminar, se confrontará con algunos estudios críticos de la exégesis literaria, con la finalidad de orientar y cuestionar el propósito de esta investigación. Por ejemplo, uno de los temas que se han abordado desde la hermenéutica es la correspondencia que se procura hallar en la obra de la violencia institucional con la formación ética de los cadetes del Colegio Militar Leoncio Prado.

La segunda parte de este trabajo consistirá en configurar una epistemología de la violencia sobre la base de conceptos sociológicos de Hannah Arendt, Johan Galtung y Jacques Lacan. Debe tomarse en cuenta que esta labor será necesaria, merced a que el escritor peruano solo brinda una percepción neutral con respecto a los acontecimientos de índole agresiva. Esa postura de por sí revela su condición conservadora y su predilección por querer mostrar un hecho desde su esencia concomitante. Por esa razón, se tendrá que forjar un paradigma que sirva como un eje que propicie la interacción de postulados teóricos con la realidad palmaria de La ciudad y los perros. Para ello, se considerará que el panorama articulado en ese discurso está adherido al contexto por el cual atravesaba el Perú a mediados del siglo XX, estribado en el proyecto de profesar la idea de modernidad y progreso desde una educación disciplinaria y castrense. Al haberse delimitado el periodo sociohistórico, se argüirá cuáles fueron las consecuencias de esa volición política desde lo que se fluctúa en el texto de Mario Vargas Llosa. Se sustentará por qué esa instruc- 
ción totémica no era efectiva en el Colegio Militar Leoncio Prado, ya que generaba daños físicos, psicológicos y sociales. En específico, los perjuicios ocasionados se percibirán en función de dos singularidades que planteaba V. P. Shupilov: la directa-física y la indirectaemocional. La primera sería de provecho para demostrar cuáles son las repercusiones provocadas a partir de la falacia de que al emplear la violencia se conseguirá la corrección y la formación de un hombre. Entretanto, la segunda se enfocaría en argumentar cuáles son las modalidades más sutiles que ejerce el perpetrador para destruir la integridad de su víctima. Para ello, se confrontará con las experiencias de los personajes principales y se fundamentarán tres variantes que permiten dilucidar las estrategias que usa el agresor, tales como la violencia psicológica activa, la psicológica pasiva y la física pasiva.

El último tratado de esta pesquisa oscilará por la noción de violencia desde la teoría narratológica de Vladimir Propp, que es formulada en Morfología del cuento (I98I). Su extrapolación será de utilidad para individualizar cada acción que realizan los protagonistas: el Jaguar, el Poeta y el Esclavo. Esa diferencia suscitará que se aprecie cómo ellos adoptan la violencia y cómo se genera su propia evolución en el decurso del tiempo. Frente a esa configuración, se reincidirá en la concepción conservadora de Mario Vargas Llosa, puesto que no se detectará ningún tipo de intervención ni favoritismo por preservar la identidad de los personajes. Su derelicción será medular, ya que facilitará que el lector forme un juicio particular en torno a los hechos que se desarrollan en la trama de La ciudad y los perros. Considerando la inexistencia de directrices desde la narración, se podrá inferir que el desempeño de los personajes determinará su complexión. Esta idea también ya había sido trabajada por el crítico literario Efraín Kristal. Sin embargo, este estudio busca complementar y reorientar esa premisa. Para ello, será necesario cotejar la parte teórica de la violencia y la narratología de Lubomír Doležel. De ese modo, se comprobará en qué medida las distintas formas de accionar constituyen ese horizonte incierto de los personajes.

\section{Posición conservadora de Mario Vargas Llosa con respecto al tratamiento de la violencia en la novela}

Para escudriñar este acápite, haré un recuento de los principales argumentos que permiten erigir el contexto adherido a la temática de la violencia en el que se origina la novela La ciudad y los perros (I963). Esta labor se hará para entender las variantes que se acoplan a un criterio conservador del autor. Para demostrar eso, organizaré esta sección de la siguiente manera: el panorama sociohistórico, la influencia del boom latinoamericano, el conservadurismo y la hermenéutica en torno a esta obra literaria de Mario Vargas Llosa.

La violencia de por sí es una situación de sufrimiento, y esta es palmaria en la coyuntura de un país. Para el caso de esta investigación, es necesario reconstruir el contexto histórico del Perú, que comprende la segunda mitad del siglo XX. Este periodo se ca- 
racterizaría por las desigualdades inmersas en los sectores político, económico y cultural. Esa inequidad revelaría la forma intrincada de regir el poder desde un Gobierno dictatorial y castrense, que estuvo a cargo de Manuel Odría a fines de los cuarenta e inicios de los cincuenta (Vilela Galván, 2003: 64). Algunos excesos que se derivaron de esa administración militar fueron el golpe de Estado y la manipulación de la gente por los medios de comunicación (Gorriti, r99I). Frente a ello, se observa el desarrollo del capitalismo, que empieza a notarse a través de jerarquías y privilegios a la élite y la clase alta. Además, se usará como pretexto la idea de ordenar, organizar y disciplinar a la colectividad con una doctrina progresista y modernizadora. Eso será motivo para que la izquierda se adscriba a un pensamiento existencial que anhela la libertad de expresión, sin importar las repercusiones morales que se generen. En suma, esa lucha consuetudinaria de intereses entre los ciudadanos y el Gobierno será una muestra de que no es palmaria una identidad homogénea en el Perú. A la vez, esa persistencia por querer alterar esa situación política hará referencia a lo que deseaba Cuba en esa etapa: crear una nueva sociedad.

Es enjundioso retomar la violencia desde la parte técnica que influyó en Mario Vargas Llosa. En la época en la que se publicó La ciudad y los perros, se manifestó un fenómeno editorial al que se le denominó el boom latinoamericano. Ese espacio propició los trabajos artísticos y literarios de jóvenes escritores e intelectuales que se distinguieron por oscilar por estilos experimentales y vanguardistas, que impulsaban la modernización y se oponían al tradicionalismo. Eso explica por qué se incorporaron tantos artificios en las obras con un abordaje inusitado. Eso se comprobó con el empleo del flashback, el contrapunto, la multiperspectiva, el monólogo interior, los vasos comunicantes y las cajas chinas. Entre otros talantes perentorios, Donald Shaw (i999: 244-245) destaca la exigencia de buscar a un lector con mayor preparación para que pudiese comprender la volición del autor. Ese requerimiento es debido a que se intenta exponer diversas posturas y representaciones de la realidad de América Latina, así como sus políticas imperantes, ya sea con la mención de la izquierda o el sector capitalista. De igual modo, se plasmó la crisis de la ética coetánea, sin que se perciba una solución al respecto. Todo este panorama coincide con la idea de que no es notoria una identidad palmaria en el país, tal como lo consideró Marina Gálvez Acero (i992: 53). Por eso, se puede inferir que uno de los propósitos inminentes de la producción artística del boom latinoamericano es exhibir la realidad desde su heterogeneidad y su intrincación, sin incluir algún tipo de afinidad por una posición o asociación política.

Habiendo desarrollado el contexto y el fenómeno editorial, es necesario precisar que existe un deseo de mostrar la totalidad sin que esta resulte afectada o alterada por intereses sociales y políticos. Esa ausencia de intervención será propia de una doctrina a la que se denomina conservadurismo, la cual se ausculta en el tratamiento que otorga Mario Vargas Llosa a su novela. En sí, este estilo de pensamiento tiende a describir los acontecimientos de forma fidedigna, exhaustiva e imparcial, sin recurrir a lo abstracto, tal como lo concretiza también el fenomenalismo. Eso de evidencia cuando el autor reconstruye un microcosmos de la realidad peruana. Para ello, se basará en patrones de las 
jerarquías militares. Asimismo, los hechos podrían estar constituidos por los paradigmas de la religión, el progreso y la naturaleza humana. Todo ello será convincente si se plasma desde su complejidad; es decir, si se exhibe desde su pluralidad y su ambivalencia, con el objetivo de preservar la tradición. Ese emprendimiento será válido y comprensible para el populismo si las pormenorizaciones son correlativas con su coyuntura concomitante y satisface los sentimientos y los intereses de los ciudadanos (Espejel Mena, 20I6: 34). Además, no se afiliará a alguna ideología ni contará con ningún compromiso político. No estará a favor de la izquierda ni la derecha (Von Beyme, I985: 9). Eso es lo que realiza el escritor peruano al exponer una obra literaria en la que se articula un malestar cultural que interfiere en el destino de los protagonistas. Sin embargo, la condición neutral del autor revela una posición implícita de la burguesía (Espejel Mena, 20I6: 25). No obstante, esa epifanía no será de relevancia para el propósito que pregona, puesto que lo que se busca es que se detecte su individualidad, su autonomía, sus principios, su percepción particular del mundo, su statu quo y su capacidad para condensar los múltiples criterios perentorios de la segunda mitad del siglo XX. Para ello, no será lisonjero que él discierna entre conceptos en conflicto, sino que se preocupe por asimilar los elementos que más le convengan para expresar un panorama sociohistórico ambicioso, como la ardua documentación y el raciocinio que requiere (Gómez Alonso, 2009: 65-66). La intención se logrará con la inserción de una secuencia de teoría-práctica o realismo-pragmatismo, que se enfoca en develar el modo de actuar frente a la sociedad. Esa orientación de sentido facilitaría que los lectores adopten una posición crítica, progresista o democrática con respecto a algún tipo de política.

Acerca de la investigación de esta obra, es necesario retomar dos premisas de la hermenéutica literaria sobre la violencia. Una de ellas se basa en juzgar el modelo militar como una doctrina que se encargará de organizar a la sociedad. Los exégetas Ramón Magráns (I994: 397) y Rodolfo Schweizer (1994: 297-299) estarían de acuerdo con esta postura. Para ellos, no se obtendría un buen resultado a partir de la formación castrense, caracterizada por la agresión física y moral. Más bien, lo que se conseguiría de esa violencia institucional sería la deshumanización del hombre (Caballero, 2OII: 203) y la adquisición tergiversada de valores y prácticas sociales (Salazar Jaque, 2005). La otra premisa en torno a la violencia radica en la crítica que se hace de la moralidad desde la novela. Para ello, Sarah Osgood Brooks (2005: I23) realizó un estudio en el que demostró que muchas de las deficiencias y los excesos que se patentizan en las acciones de los personajes son una representación del malestar cultural que padece el Perú en la actualidad. Y esa inferencia es válida, ya que la violencia que se plasma en el texto tiene las mismas repercusiones en la sociedad vigente. Sin embargo, es cuestionable que el autor solo se haya enfocado en mostrar las causas y los efectos de una acción. Por ello, es meritorio que se detecte una finalidad más allá de lo explícito. Frente a esa inquietud, José Miguel Oviedo (I982) ya había identificado que el propósito de Mario Vargas Llosa consistió en exhibir la composición humana, en cuanto que esta atraviesa por cambios que facilitan que se alcance la convivencia armoniosa en la sociedad. Esa percepción antagónica aporta a la 
comprensión del panorama que afrontó el país durante la segunda mitad del siglo XX.

Con estos cuatro abordajes que permiten auscultar el entorno en el cual se fluctuó La ciudad y los perros, se colige que existe una pretensión de innovar la presentación del proyecto literario, además de que se revela un horizonte conflictivo de la realidad peruana, con la intención de que el lector erija un propio criterio de la situación y los hechos que se articulan en la novela. Esa volición solo se logrará con el tratamiento adecuado que le ha brindado el autor y su adhesión a su postura conservadora y totalizante.

\section{Epistemología de la violencia}

Todo acto de agresión supone un abuso de poder que se realiza desde una relación de dependencia. Este proviene de cualquier ámbito, ya sea familiar o institucional. Su proyección causa detrimento en la integridad física, psicológica y social del individuo, tanto así que termina significando una amenaza para su desarrollo físico y psicosocial. Por error, los padres piensan que al exponer a su hijo en un colegio militar le será útil para disciplinarlo. Perciben los castigos como un método correctivo. Esa ideología será propia del aforismo conservador, merced a que esta procura un cambio a partir del respaldo del orden que patrocinan las instituciones, por encima de la libertad (Marco, 2005: I3I). En ese sentido, asumir que la disciplina será un elemento importante para la reparación y el adiestramiento de los cadetes provocará una reacción en el lector, puesto que se está mostrando una realidad de la que es imposible no formarse un criterio al respecto. No obstante, una persona ajena al adoctrinamiento castrense opinará que esa instrucción es perjudicial para los muchachos. Esa fue la posición que adoptó Sharon Magnarelli (I976: 4O-42) al referirse que esa enseñanza no era compatible para la evolución de las personas; más bien, consistiría en un acto de hipocresía, porque se concluía aprendiendo antivalores. Por ende, ese tratamiento solo repercutirá con deficiencias. Para Johan Galtung (Domenach, et al. I981: 98), esto conllevará una represión en la que se prohíbe la libre manifestación de los derechos humanos. Eso equivale a sostener que esa condición únicamente reduce el potencial del alumnado. Es intolerable. Y peor será si es que dentro de las aulas los mismos estudiantes practican la violencia, sin ser supervisados. A ese fenómeno de agresión escolar, Cerezo lo denomina bullying (Hernández Granda, 2ooI: 27). Pese a corroborar variantes, los efectos que genera la violencia son los mismos en cualquier sector. Para Hannah Arendt (2008: IO), esa realidad es un gran problema, ya que se intenta incorporar estrategias de agresión para erradicar un malestar. Se persiste en ese propósito, sin considerar que existen medios más transigentes y comprobados.

Desde la perspectiva psicoanalítica, Jacques Lacan (I998: 353) define la violencia como el acto nocivo que se repite con monotonía. Su víctima padecerá maltrato emocional y tendrá una composición que revele la carestía de amor. Ese desempeño perjudicial podría adoptar diferentes significaciones, como también no. Sin embargo, sus funciones se evidenciarán en los protagonistas en cuanto que ellos susciten el desarrollo de la intriga; 
en rigor, su rol agente-personaje provocará el avance de un nudo a otro (Doležel, I999: 9o). Esa secuencialidad es importante para hallar el aliciente del autor. Es más, servirá para reconocer cómo se origina la violencia y a qué se debe que esta se extrapole sobre ámbitos perentorios. Ante esa disposición de distinguir las diversas funciones que asume esta categoría, Mackenzie (Domenach, et al. I98I: I92) sostiene que lo más preferible es formular una conceptualización taxonómica. Así, se delimitará el mecanismo operacional de cada rubro que actúa en torno a la violencia, pues se sabe que un modo exclusivo de maltrato es inverosímil. Frente a esa dispersión de elementos, propondré dos maneras de corroborarla según V. P. Shupilov (Domenach, et al. ı98ı: ı6o). La primera es la activa y directa. Esta se producirá cuando prevalezca un abuso o una derelicción física. La segunda es la pasiva e indirecta, la cual se generará cuando se note un maltrato y un desarraigo emocional. Ambas modalidades se dilucidarán a continuación.

\section{I. La forma activa y directa de la violencia en La ciudad y los perros}

Norbert Elías (1987: 456) indica que este tipo de violencia física es de utilidad para adiestrar a las personas que se reclutan en los cuarteles. A ellos no les afectará siempre y cuando no sean expuestos a eventualidades extremas, como cuando se someten a épocas de guerra o subversión social. Por ello, esa manera de tratar queda reducida a un monopolio de un grupo de especialistas, que se encarga de que se logren cambios y acoplamientos del individuo a ese espacio militar. Para que ese procedimiento sea eficaz, el sujeto tendrá que claudicar de sus condicionamientos sociales tradicionales y asimilar un vademécum bajo la égida del maltrato (Boldori de Baldussi, I974: 22). Esos actos se harán de forma pública; es decir, serán observables. Frente a ese panorama incierto, se intenta brindar una explicación que procure aminorar la percepción negativa que se le otorga a este tipo de instrucción castrense. Verbigracia, se cree que con ese adoctrinamiento uno se hará más fuerte de carácter, como también se hace una asociación idónea de que quien golpea adopta un nivel de supremacía. Este puede ser un padre, un maestro, un hombre poderoso, una autoridad o un estudiante con privilegios. Sin embargo, el resultado nocivo será más notorio. Las agresiones de índole física causarán una lesión irrevocable, dependiendo de su intensidad (Ruiz Carbonell, 2002: I64). Incluso, podría generar un detrimento cerebral o la muerte. Esa forma de proceder con sus consecuencias se aprecia en La ciudad y los perros. Sobre todo, es peculiar cuando los cadetes de grados mayores abusan de los ingresantes del Colegio Militar Leoncio Prado. Eso se corrobora a continuación:

El de la derecha golpeó primero y el Esclavo sintió fuego en el antebrazo. El de la izquierda lo hizo casi inmediatamente.

-Bueno -dijo la voz-. ¿Cuál ha pegado más fuerte?

-El de la izquierda.

- ¿Ah, sí? -replicó la voz cambiante-. ¿De modo que yo soy un pobre diablo? A ver, vamos a ensayar de nuevo, fíjese bien. 
El Esclavo se tambaleó con el impacto, pero no llegó a caer: las manos de los cadetes que lo rodeaban lo contuvieron y lo devolvieron a su sitio.

-Y ahora, ¿qué piensa? ¿Cuál pega más fuerte?

-Los dos igual.

-Quiere decir que han quedado tablas - precisó la voz-. Entonces tienen que desempatar.

Un momento después, la voz incansable preguntó:

-A propósito, perro. ¿Le duelen los brazos?

-No - dijo el Esclavo.

Era verdad; había perdido la noción de su cuerpo y del tiempo (Vargas Llosa, 2OI2: $59-60)$.

El panorama violento que se plasma desde el sector escolar va adquiriendo múltiples variaciones. Esos continuos cambios solo confirman la permisibilidad de la agresión y la omisión a cualquier tipo de enmendadura efectivo. Al respecto, Eva Hernández Granda (20OI: 29) precisa que esas conductas belicosas en los adolescentes son un indicador de que se están emulando patrones precedentes. Estos se actualizarán con la iteración de los nuevos agentes. Esta situación también es observable en otras interacciones, como las que están dirigidas a los adultos. De por sí, estas son consideradas de otra forma. Más que nada, se conocen como desafíos, que serán representados por medio de la mala voluntad, la desobediencia o la infracción de las normas del grupo. Eso se evidencia cuando el Jaguar es retenido por el teniente Gamboa, al ser acusado como ladrón y principal sospechoso del asesinato de Ricardo Arana. La actitud rebelde que expondrá hacia su superior demostrará esa deficiencia:

¿Cuántos roperos ha abierto, hace cuánto tiempo que roba a sus compañeros?

- ¿Yo? -Gamboa se desconcertó un momento: el Jaguar lo miraba con ironía. Repitió, sin bajar la vista-: ¿Yo?

-Sí -dijo Gamboa; sentía que la cólera lo dominaba-. ¿Quién mierda sino usted?

-Todos -dijo el Jaguar-. Todo el colegio.

-Miente -dijo Gamboa-. Es usted un cobarde.

-No soy un cobarde - dijo el Jaguar-. Se equivoca, mi teniente.

-Un ladrón -añadió Gamboa-. Un borracho, un timbero, y encima un cobarde.

¿Sabe usted que me gustaría que fuéramos civiles?

-¿Quiere pegarme? - preguntó el Jaguar [...].

- ¿Por qué mataste a Arana? -dijo Gamboa-. Responde. Todo el mundo está enterado. ¿Por qué?

-¿Qué le pasa a usted? - dijo el Jaguar. Había pestañeado una sola vez.

-Responde a mi pregunta.

- ¿Es usted muy hombre? -dijo el Jaguar. Se había incorporado. Su voz tembla- 
ba-. Si es usted tan hombre, quítese los galones. Yo no le tengo miedo [...]. Quítese los galones [...]. Usted puede ser más fuerte, pero no le tengo miedo (Vargas Llosa, 2OI2:

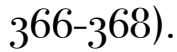

La incriminación de robo que hace el teniente Gamboa al Jaguar será la que desencadene la falta de respeto del cadete a su superior. No obstante, es enjundioso precisar en torno al concepto de hurto. Para Johan Galtung (Domenach, et al. 1981: 98), se trata de la epifanía de una violencia de índole instrumental, que compete a un delito contra la propiedad. En su mayoría, se justifica que ese proceder se respalda de la carencia de recursos que tiene el perpetrador. Sin embargo, en la obra literaria ese no es un requisito indispensable. El personaje coge las pertenencias de otros para mantener la imagen temeraria que proyecta al resto de alumnos. En ese sentido, el haber actuado de una manera corrosiva y al ser descubierto por su mayor le generará una segunda atmósfera: un enfrentamiento cínico. Para Doležel (I999: I25), este tipo de situaciones expone la pérdida de control de los participantes. Eso provoca que el conflicto se intensifique y las pasiones impulsivas e irracionales sean evidentes. No importará que ese clímax conlleve un combate, puesto que se considera que ese intercambio físico de acciones transitivas no revertirá la acusación inicial (Doležel, ı999: ı64). Esa circunstancia se acopla a la naturaleza de una competencia, ya que el pleito irá acrecentándose a medida que se manifiesten las limitaciones de cada uno. Con respecto a esas restricciones, la novela de Mario Vargas Llosa muestra desniveles existentes en cuanto la edad de cada estudiante. Se supone que un alumno de quinto año tendrá un mejor rendimiento para pelear que otro de grado inferior. Por el contrario, los elementos que destacan en La ciudad y los perros con mayor determinación se rigen por la supremacía de fuerza física y mental, junto con la adquisición de experiencia en lucha. El Jaguar es un exponente de esa distinción de violencia. Él conoce más de rencillas que sus demás compañeros. Ante esa complexión que adopta, se derivan algunas peculiaridades que permiten identificar el desarrollo de un combate. En un primer caso, se observa cómo este personaje se hace respetar por los cadetes de grados mayores. Eso lo logrará al no dejarse golpear por ellos ni tampoco facilita que se le iguale en condiciones. Incluso, él será superior a ellos.

-No pelearon mucho rato - dijo Cava-. Y me di cuenta por qué le dicen Jaguar. Es muy ágil, una barbaridad de ágil. No crean que muy fuerte, pero parece gelatina, al Gambarina se le salían los ojos de pura desesperación, no podía agarrarlo. Y el otro, dale con la cabeza y con los pies, dale y dale, y a él nada. Hasta que Gambarina dijo: "Ya está bien de deporte; me cansé”, pero todos vimos que estaba molido (Vargas Llosa, 2OI2: $64)$.

Esa supremacía física y mental en el Jaguar será perentoria para aludir a una forma heteróclita e innovadora de afrontar las colisiones tradicionales del Colegio Militar Leoncio Prado. Asimismo, esa circunstancia inusitada reanuda el objetivo de los escritores del 
boom latinoamericano, quienes trataban de proyectar un desenvolvimiento diferente en cualquiera de los sectores de la realidad. Con este personaje, se consigue la apreciación de un nuevo rumbo en función del tema social de la violencia, sin que el autor manifieste su aprobación o su rechazo. Esa imparcialidad confirmará su postura conservadora y servirá para comprender el texto a partir de su ipseidad. Más adelante, la trama revela otros acontecimientos que permiten distinguir un segundo rasgo de las disputas. Esta vez se tomará como ejemplo el enfrentamiento que tiene el Jaguar con el Poeta. Ante ello, se sabe por antonomasia quién cuenta con una mayor capacidad física. Sin embargo, Alberto Fernández se arriesgará a pelear con él por su impulso de querer vengar la muerte del Esclavo. De ello, es meritorio destacar su osadía, aunque el corolario no será divergente.

Cuando recibía los golpes del Jaguar en el suelo del calabozo, donde se revolcaba en silencio, no había sentido dolor alguno, solo humillación. Porque a los pocos minutos de comenzar, se sintió vencido: sus puños y sus pies apenas tocaban al Jaguar, forcejeaba con él y al momento debía soltar el cuerpo duro y asombrosamente huidizo que atacaba y retrocedía, siempre presente e inasible, próximo y ausente. Lo peor eran los cabezazos, él levantaba los codos, golpeaba con las rodillas, se encogía; inútil: la cabeza del Jaguar caía como un bólido contra sus brazos, los separaba, se abría camino hasta su rostro y él, confusamente, pensaba en un martillo, en un yunque. Y así se había desplomado la primera vez, para darse un respiro. Pero el Jaguar no esperó que se levantara, ni se detuvo a comprobar si ya había ganado: se dejó caer sobre él y continuó golpeándolo con sus puños infatigables hasta que Alberto consiguió incorporarse y huir a otro rincón del calabozo. Segundos más tarde había caído al suelo otra vez, el Jaguar cabalgaba nuevamente encima de él y sus puños se abatían sobre su cuerpo hasta que Alberto perdía la memoria. Cuando abrió los ojos estaba sentado en la cama, al lado del Jaguar y escuchaba su monótono resuello. La realidad volvía a ordenarse a partir del momento en que la voz de Gamboa retumbó en la celda (Vargas Llosa, 2OI2: 4IO-4II).

En ese pasaje, el Jaguar tiene la oportunidad de demostrar una vez más que su poder es inminente con respecto al de otros alumnos. Esa situación es un efluvio para él, pero su epifanía violenta no será motivo de vanagloriar. Para finalizar, se desarrolla un caso que revierte la condición de este personaje. Un conjunto de cadetes lo vencerá por creer que él los ha delatado e involucrado en un problema mayor con la institución.

Lo dejaron llegar hasta donde estaban Arróspide y el Boa, revolcándose en el suelo, medio cuerpo sumergido bajo la litera de Montes e, incluso, permanecieron inmóviles cuando el Jaguar, sin inclinarse, comenzó a patear al brigadier, salvajemente, como a un costal de arena. Luego, Alberto recordaba muchas voces, una súbita carrera: los cadetes acudían de todos los rincones hacia el centro de la cuadra. Él se había dejado caer en el lecho, para evitar los golpes, los brazos levantados como un escudo. Desde allí, emboscado en su litera, vio por ráfagas que uno tras otro los cadetes de la sección arremetían 
contra el Jaguar, un racimo de manos lo arrancaba del sitio, lo separaba de Arróspide y del Boa, lo arrojaba al suelo en el pasadizo y, a la vez que el vocerío crecía verticalmente, Alberto distinguía, en el amontonamiento de cuerpos, los rostros de Vallano y de Mesa, de Valdivia y Romero, y los oía alentarse mutuamente - “¡denle duro!”, "¡isoplón de porquería!”, “¡hay que sacarle la mugre!”, “se creía muy valiente, el gran rosquete”- y él pensaba: “Lo van a matar. Y lo mismo al Boa”. Pero no duró mucho rato. Poco después, el silbato resonaba en la cuadra, se oía al suboficial pedir tres últimos por sección y el bullicio y la batalla cesaban como por encanto (Vargas Llosa, 2OI2: 425-426).

La derrota por la que pasa el Jaguar concluye en que la dinámica del enfrentamiento es un tanto superficial y fortuita. No está supeditada a tener mayor experiencia o agresividad. Tampoco, esta no está determinada por atmósferas específicas de la violencia. Más bien, lo que se logra inferir es que la naturaleza interviene en su condición ambivalente y neutral. Y esta es relatada desde la percepción conservadora del escritor peruano. Por ende, la versatilidad muestra una vez más la variación por la que atraviesan los actantes de esta novela.

\subsection{La forma pasiva e indirecta de la violencia en La ciudad y los perros}

Este tipo de agresión emerge desde lo emocional y lo psicológico. Su objetivo es destruir los sentimientos y la autoestima de la víctima. Para conseguirlo, recurrirá a denigración constante, control de sus acciones y bloqueo de su autenticidad. A ello, también se agregan otros elementos, como el de la invalidación, la amenaza, la crítica, la discriminación, la descalificación, la exclusión, el aislamiento, el hostigamiento, el rechazo, la difamación, el chantaje y la coacción. Muchas veces, estas acciones serán difíciles de auscultar, por lo que la perpetración proseguirá. Incluso, las agresiones verbales serán más identificables a diferencia de las otras manifestaciones, que son más sutiles. Ese procedimiento repercutirá en los espacios emocional e intelectual del afectado, tanto así que terminará dudando de su propia realidad. Se desequilibrará y se limitará a sobrevivir con recursos básicos. Esa pretensión fue detectada por la crítica literaria Rosa Boldori de Baldussi (I974: 22), quien asevera que esas estrategias solo producirán que la violencia se intensifique en quienes buscan una reparación a nivel social. Reanudando La ciudad y los perros, es enjundioso apreciar cómo se aborda a la mujer de acuerdo con este paradigma de agresión social, tal como ocurre con Teresa. La presencia de los celos y el acoso serán una muestra de esa violencia emotiva por la que está atravesando. Esta se evidenciará por medio del uso del lenguaje belicoso; sobre todo, si es un escándalo. Este último será palmario cuando exista una composición modelada de intercambios íntimos, en los que los personajes exponen una secuencia verbal distinguida por la disputa y el dramatismo. A ello, se incorporarán elementos gestuales que irán en aumento (Doležel, ı999: I25). Para el caso de la novela, retomaré dos ejemplos en los que se observa el funcionamiento del escándalo. Uno de ellos es notorio cuando el Poeta enfrenta al Jaguar desde la celda. Esa situación conflictiva provocará que se profieran palabras con mucha agresividad: 
-Eres una mierda, Jaguar -dijo Alberto-. Me gustaría que te metieran en la cárcel [...]. ¿Has oído lo que he dicho? [...]. Una mierda [...]. Un asesino. Tú mataste al Esclavo [...]. Eres un desgraciado, Jaguar. Ahora te van a expulsar. ¿Sabes cuál va a ser tu vida? La de un delincuente, te meterán a la cárcel tarde o temprano [...]. Tú no eres más hombre que nadie [...]. Eres un asesino y no te tengo miedo. Cuando salgamos de aquí vas a ver.

- ¿Quieres pelear conmigo? - dijo el Jaguar.

-Sí (Vargas Llosa, 20I2: 397-398).

Los diálogos que se desarrollan en esa oportunidad incitan a la lucha, puesto que lo que más prevalece son las ofensas por encima de cualquier intercambio apaciguado de palabras. Un caso adicional a este tipo de manifestaciones es cuando el Jaguar es acusado de "soplón” por los cadetes de su sección. Esa atribución a la que el personaje considera desatinada emerge en él que se desempeñe con violencia. Esa escena de la disputa se mostrará a continuación.

-Muchachos - gritó Arróspide-. Ustedes lo están viendo. Ha sido él. Ni se atreve a negarlo. Es un soplón y un cobarde. ¿Me oyes, no, Jaguar? He dicho un soplón y un cobarde [...].

-Solo veo caras de cobardes - dijo el Jaguar-. Nada más que eso. Caras de maricones, de miedosos [...].

-Griten, muchachos -dijo Arróspide-. Díganle en su cara lo que es. Díganselo $[\ldots]$.

Arróspide coreaba “soplón, soplón”, frenéticamente, y de distintos puntos de la cuadra, aliados anónimos se plegaban a él, repitiendo la palabra a media voz y casi sin abrir la boca (Vargas Llosa, 2OI2: 424-425).

Ambos casos terminan en peleas que suscitarán daños físicos. No obstante, esa modalidad no es la única manera de apreciar este tipo de acontecimientos nocivos. Otra forma de violencia pasiva e indirecta se cerciora cuando el perpetrador abusa de los recursos de su víctima para no asumir alguna responsabilidad. Eso se constata cuando el Jaguar ordena que el Esclavo sustituya su función de imaginaria. También se coteja cuando se ausculta que el personaje siente temor por las repercusiones que pudiera generar si acusa a quien robó el examen de Química. Él sabe que ese silencio está perjudicándolo, ya que se encuentra retenido en la institución hasta que se desentrañe la verdad. Es más, el culpable se halla en libertad y goza de salidas a diferencia de Ricardo Arana. Con todo ello, se demuestra que este tipo de violencia emocional se puede reconocer a través de la concatenación de las acciones de los personajes. Sin embargo, será necesario aludir a la estratificación que se efectúa en torno a su aprendizaje. De esa taxonomía, se corrobora la eclosión de tres variantes: la psicológica activa, la psicológica pasiva y la física pasiva.

La primera forma de violencia emocional es la agresión psicológica activa. Esta 
consiste en el acoso verbal habitual. Se acota por intermedio de insultos, críticas, descalificaciones, ridiculizaciones, actitudes o comportamientos afines. Al respecto, el exégeta José Luis Martín (I979: 30-3I) había detectado la incorporación de estos talantes en la narrativa de Mario Vargas Llosa. Y agrega que prevalece una recurrencia a lo "feísta", que se entiende como el empleo deliberado de palabras soeces y vulgares. Todas estas expresiones conllevarán un detrimento sistemático de la autoestima o algún trastorno en el desarrollo emocional, social e intelectual del individuo. Asimismo, estos actos no solo se asocian con lo que se recibe directamente, sino que también repercute al ser testigo de cualquier manifestación de violencia. En general, el primer encuentro con este tipo de perpetración se apreciará en el ámbito familiar. En la novela, muchos de los personajes muestran una infancia caracterizada por la inclusión de elementos nocivos en las relaciones conyugales. Eso se evidencia en el caso del Poeta, quien cuenta con un padre que se responsabiliza de esa forma de actuar y una madre que cumple el rol de víctima. Esa configuración se constata en los siguientes diálogos.

-Carmela -dijo el padre alegremente-. Ven, hija, vamos a conversar un momento. Podemos hacerlo delante de Alberto, ya es todo un hombrecito [...]. Calma -repuso el padre-. Somos gente civilizada. Todo se puede resolver con serenidad.

-¡Eres un miserable, un perdido! -gritó la madre, súbitamente cambiada: mostraba los puños y su rostro, que había perdido toda docilidad, estaba encarnado; sus ojos relampagueaban-. ¡Fuera de aquí! Esta es mi casa, la pago con mi dinero [...].

-Carmela -dijo el padre-, tranquilízate. No quiero pelear contigo. Un poco de paz. No puedes seguir así, es absurdo. Tienes que salir de esta casucha, tener sirvientas, vivir. No puedes abandonarte. Hazlo por tu hijo.

- ¡Fuera de aquí! -rugió la madre-. Esta es una casa limpia, no tienes derecho a venir a ensuciarla. Vete donde esas perdidas, no queremos saber nada de ti; guárdate tu dinero. Lo que yo tengo me sobra para educar a mi hijo.

-Estás viviendo como una pordiosera -dijo el padre-. ¿Has perdido la dignidad? ¿Por qué demonios no quieres que te pase una pensión?

-Alberto - gritó la madre, exasperada-. No dejes que me insulte. No le basta haberme humillado ante todo Lima, quiere matarme. ¡Haz algo, hijo!

-Papá, por favor -dijo Alberto, sin entusiasmo-. No peleen.

-Cállate -dijo el padre. Adoptó una expresión solemne y superior-. Eres muy joven. Algún día comprenderás. La vida no es tan simple [...].

-¡Cínico! -gritó la madre y volvió a agazaparse [...].

La madre lloraba ahora a gritos y, entre sollozos, insultaba al padre y lo llamaba "adúltero, corrompido, bolsa de inmundicias" (Vargas Llosa, 2OI2: IO4-IO6).

La situación que se muestra es lamentable para la madre, y repercutirá en la constitución familiar; en especial, en Alberto Fernández, quien se encuentra en una etapa plena de desarrollo. Esa consecuencia permitiría hacer referencia a la segunda modalidad 
de este concepto: la agresión psicológica pasiva o el abandono emocional. Esta consiste en el descuido crónico de las necesidades evolutivas del hijo, como la falta de estimulación cognitiva o afectiva de uno de los progenitores. Sin embargo, lo más perjudicial es la privación sistemática de los buenos sentimientos o la falta de corrección ante malos comportamientos. En el caso del Jaguar, él forjará actitudes negativas, porque comparte un grupo social que se dedica al robo, tal como se aprecia al tener una amistad como el flaco Higueras. Ante ello, no hay quién pueda orientarlo éticamente. La representación de ese padre que debe increpar, prohibir y dirigir está en la postrimería en ese instante. Y su ausencia conforma parte de su niñez.

La tercera modalidad se basa en el maltrato físico pasivo o la negligencia. Esta variante es crónica. Esta se enfoca en el control de las necesidades físicas y básicas del menor, como su alimentación, su educación, su salud y su preservación. Cuando estas no son resguardadas con éxito por los adultos, se produce este tipo de agresión, que repercutirá en su integridad física y psicológica. Verbigracia, el progenitor del Esclavo no crio a su hijo desde la niñez. Esa realidad se la hace saber su mamá en uno de sus diálogos: “Tu papá no estaba muerto, era mentira. Acaba de volver de un viaje muy largo y nos espera en Lima” (Vargas Llosa, 20I2: I5). Eso implica que el menor no ha tenido los cuidados adecuados y que en ese momento presente algún modo de perturbación emocional. El personaje no sentirá confianza hacia su padre, además de que lo contemplará de forma insulsa.

Eludía a sus padres y les hablaba solo con monosílabos. “QQué te parece tu papá?”, le preguntó un día su madre. "Nada”, dijo él, "no me parece nada”. Y otro día: “¿Estás contento, Richi?”. "No". Al día siguiente de llegar a Lima, su padre vino hasta su cama y, sonriendo, le presentó el rostro. "Buenos días", dijo Ricardo, sin moverse. Una sombra cruzó los ojos de su padre. Ese mismo día comenzó la guerra invisible. Ricardo no abandonaba el lecho hasta sentir que su padre cerraba tras él la puerta de calle (Vargas Llosa, 20I2: 94).

Aparte de que esa derelicción paterna es perjudicial para el Esclavo, crea una atmósfera incómoda, en la que Ricardo Arana no termina de convencerse del rol que cumple cada uno en ese espacio vital. Su percepción intrincada no favorecerá en su desarrollo personal, pues no se siente identificado con la figura subrepticia de la masculinidad de su progenitor.

\section{La función actancial de los protagonistas de La ciudad y los perros con la incorpo- ración de la violencia}

En esta sección, se reanudará la importancia que posee la configuración de los personajes de la novela de Mario Vargas Llosa desde sus propios pensamientos y ac- 
ciones. Para ello, se confrontará con el texto de Vladimir Propp, Morfología del cuento (I98I). Las teorías que se fluctúan allí son ineludibles para detectar la formación de las identidades del Jaguar, el Poeta y el Esclavo que se muestran por medio de secuencias narrativas. El modo como se presente se adscribirá a un ritmo recíproco y reiterativo, debido a que articula una dinámica de asimilación y rechazo de la violencia. Para recordar, esa distribución de los actantes fue trabajada por Efraín Kristal (2OI2: 555-556). Él formuló que muchos de los personajes se hallaban expuestos a una constante lucha interna entre elegir la práctica del bien o el mal, además de que ellos no se responsabilizarían de solucionar el problema. Esa inferencia hace considerar la ideología conservadora a la que se afilia el escritor peruano, ya que adopta una complicidad de lo que ocurre, en vez de optar por una postura favorable o desfavorable. Con ese lineamiento, es válido sostener que esa imparcialidad por parte del autor permitirá que los personajes se exhiban en su ipseidad y que se ausculten patrones que rigen a la sociedad de mediados del siglo XX. Ante este panorama circunscrito, será fundamental hacer una descomposición de las principales funciones que desempeñan los protagonistas, de acuerdo con el decurso del tiempo.

\section{* El Jaguar:}

I. Tiene una mala formación familiar.

II. Conoce a Teresa. Se enamorará de ella y la visitará con frecuencia.

III. Practica malos hábitos al juntarse con el flaco Higueras.

IV. Asumirá costumbres violentas para acoplarse a las vivencias que exige el Leoncio Prado.

V. Se rebela ante los alumnos del cuarto año y los derrota.

VI. Crea una banda delincuencial en la institución, a la que denomina el Círculo. Él tomará el cargo principal.

VII. Impone su posición autoritaria y temeraria. Asimismo, se hace llamar el Jaguar.

VIII. No se deja golpear por nadie. Su complexión temeraria infunde miedo y respeto al resto de cadetes.

IX. Cuenta con la necesidad de aprobar el examen de Química, a pesar de que él no es estudioso.

$X$. Considera la existencia de la prohibición de acceder al examen por parte de las autoridades del colegio.

XI. Recurre al robo para aprobar el examen. Un integrante del Círculo lo hará.

XII. Chantajea a sus compañeros. Opta por vengarse del soplón.

XIII. Su aliado, el serrano Cava, es delatado. Por lo tanto, resulta afectado. 
XIV. Odia al supuesto delator. Deduce que es el Esclavo.

XV. Realiza la venganza. Asesina a Ricardo Arana.

XVI. Es sancionado por la delación que hizo Alberto.

XVII. Niega su condición de asesino del Esclavo.

XVIII. Sus compañeros se rebelan ante él y lo golpean. Injustamente, lo consideran "soplón”.

XIX. Quienes lo marginan se decepcionan de él y sienten cólera.

XX. Se arrepiente y revela los detalles del asesinato. Asumirá el cargo de homicida.

XXI. Su rol de culpable no es considerado. Es exonerado para que la institución no tenga una mala reputación.

XXII. Demuestra a Teresa que es muy agresivo por golpear a un chico que la acompañaba.

XXIII. Luego de mucho tiempo, trata de progresar con una función más correcta. Se convertirá en una persona de bien.

XXVI. Se casa con Teresa.

\section{* El Poeta:}

I. Tuvo una mala formación familiar.

II. Ingresa al Colegio Militar Leoncio Prado, donde existen jerarquías que no deben ser vulneradas.

III. Es agredido por los alumnos de cuarto año al ingresar.

IV. Reconoce su ubicación entre el bien y el mal, ya que identifica de forma correcta que el Jaguar y el Círculo son representaciones del terror en su institución. Es más, sabe a quiénes hacerles sus bromas.

V. Tiene una vida cómoda y amistades de su misma condición social fuera del colegio.

VI. Hace novelitas porno que vende a sus compañeros. Con lo que recauda, compra cigarrillos.

VII. Entabla una amistad con el Esclavo.

VIII. Conoce a Teresa por encargo de Ricardo Arana.

IX. Se enamora de ella.

X. Es castigado por el robo del examen de Química, al igual que otros de sus compañeros.

XI. Averigua que el delator del robo ha sido el Esclavo. 
XII. Queda afectado por la muerte de Ricardo Arana. Sentirá ira y depresión descomunales. XIII. Acusa a sus compañeros de hacer malas prácticas dentro del colegio y culpa al Jaguar como presunto asesino del Esclavo.

XIV. Es retenido en la misma prisión donde está el Jaguar.

XV. Se enfrenta a él.

XVI. Las autoridades de la institución hacen que retire su denuncia, puesto que es chantajeado de ser expulsado por propagar sus novelitas porno.

XVII. Se resigna a adaptarse a las circunstancias, con la volición de que hará justicia en algún momento, con respecto al homicidio de su compañero.

\section{* El Esclavo:}

I. Tuvo una mala formación familiar.

II. Conoce a Teresa, de quien se enamorará, sin que ella lo sepa.

III. Se le muestran costumbres violentas desde que ingresa al Colegio Militar Leoncio Prado. Deberá ser golpeado por los cadetes de cuarto año.

IV. Es agredido, golpeado e insultado por la mayoría de alumnos de la escuela.

V. Se le asigna la función de imaginaria para que cuide el entorno de la institución.

VI. Se percata de que el serrano Cava ha sido el culpable del robo del examen de Química.

VII. Se hace amigo del Poeta y le encarga informarle su estado de retención a Teresa.

VIII. Es castigado por pasarle las respuestas del examen a Alberto.

IX. En la escuela, se le sanciona con la privación de su libertad, hasta que no se descubra al culpable del robo de la prueba.

$X$. Atraviesa una etapa de angustia: extraña a Teresa, no soporta estar tanto tiempo encerrado y siente cólera hacia el Círculo por no habérsele castigado por la fechoría.

XI. Delata al serrano Cava.

XII. Tiene miedo por lo que podría acontecer después; además, se enferma.

XIII. Es asesinado por el Jaguar.

Para analizar estas secuencias discursivas adscritas a la violencia, es neurálgico dilucidar la epistemología de las acciones. Al respecto, Jacques Fontanille (2OOI: I25) parte de la noción de que su acepción es abstracta, y está orientada a modificar el estado primario de los personajes. De esa manera, se puede explicar cómo alguno de los protagonistas 
asume un rol violento en el transcurso de los hechos. Para complementar esta información, Salvador Mas (Aristóteles, 2000: 26) especifica que la acción no es solo lo que se observa en la representación dramática, sino que consiste en todo lo que se aprecia en la realidad, como el movimiento corporal. Su composición es singular y está dispersa por doquier. Asimismo, interesa saber cómo se distribuyen en el tiempo. Para ello, Wolfgang A. Luchting (1976), la Comisión del Senado de la República sobre Violencia y Pacificación (Rubio, Mac Gregor y Vega, I990: 23) y Lubomír Doležel (I999: 92) sostienen que las acciones están condicionadas a los acontecimientos y las circunstancias sociales. Por esa razón, si se percibe una atmósfera violenta, es oportuno que se constate una conmutación de la conducta del individuo; es decir, alguien que patrocina el maltrato, el abuso psicológico o la exclusión será el culpable de que la moralidad del resto de personas se perturbe. Esos cambios pueden tener un intervalo mínimo o un largo periodo, según sea el caso. También, es un suceso intencional que permite que se trastoquen los estados. Dirige el avance de un estado inicial representado a un estado final anticipado, considerando que se trata de una orientación hacia el futuro del agente.

Para comprender a cabalidad la composición de las acciones, es preferible fundamentar las categorías afines que propone Lubomír Doležel (I999). Él hace una nomenclatura de acuerdo con seis patrones: la conciencia, la iteración, la duración, la creatividad, la producción o la destrucción y la transitividad o la intransitividad.

Primero, las acciones conscientes son las que poseen una intención (Doležel, I999: 94). A menudo, estas pueden obviarse por la frecuencia con la que se efectúan. Eso acontece con las rutinas, que se ejecutan casi con automatismo y que dependen de las destrezas innatas o adquiridas del agente. En el caso de la obra literaria, se observa esa cualidad consuetudinaria en los protagonistas. Verbigracia, el Jaguar tiende a golpear a los demás y desempeñarse con violencia. El Poeta cuenta con la facilidad de escribir novelitas pornográficas. Y el Esclavo es un estereotipo perentorio de quien practica el bien moral.

Segundo, las acciones iterativas se encuentran subordinadas funcionalmente a los actos individuales (Doležel, I999: 92). Eso se aprecia cuando el Jaguar asume que tiene que desenvolverse con maldad, porque él es el líder del Círculo. Su proceder tendrá que ser inminente para que los integrantes de esa banda puedan eximirlo.

Tercero, las acciones durativas o las macroacciones modifican la proyección de uno con constancia (Doležel, r999: 94). Eso significa que terminarán siendo corregidas, moduladas o canceladas. Sin embargo, estas no afectan en absoluto el rol estratégico de las personas. Ese indicador se corrobora en el desempeño de Alberto Fernández, quien asimila con periodicidad distintos comportamientos según cada situación. Su posición es identificable entre el bien y el mal, y a partir de allí se intimidará, sufrirá, peleará, delatará o recurrirá a amistades confiables fuera de su institución.

Cuarto, las acciones creativas involucran la creación de artefactos (Doležel, I999: 9I-92). Eso se constata en objetos que sobreviven al acto y existen independientemente del agente que los originó. Por medio de estas, se acrecienta el mundo y se expande la re- 
serva de sus objetos. Esa variante se cerciora en la mentalidad del Poeta, quien cuenta con la potestad de inventar historias pornográficas y proporcionárselas a sus compañeros de su escuela. Esa interacción será perjudicial, porque su creación perturbará y corromperá la integridad psicológica de los muchachos. Es más, el discurso ofrecido se encontrará desarraigado de su autor. Se pondrá en venta y se propagará en las aulas.

Quinto, un rasgo importante para comprender las acciones es su productividad o su carácter destructivo. Para Doležel (I999: 9I), ese factor será perentorio para lograr transmutaciones radicales en el mundo. Para el autor, esto se irá consiguiendo por medio de dos modalidades: con la anulación de un objeto existente o la innovación. Cualquiera de esos dos procedimientos asegurará la dinámica orientada a su eficacia. Esa ideología se aprecia en la configuración de la novela. Con respecto a eso, la exégeta literaria Helena Beristáin (I997: I78-I79) indicó que era fundamental la incorporación y el retiro de elementos que constituyeran la identidad de los personajes, así como sus gestos o sus comportamientos. Esa peculiaridad es notoria cuando el Jaguar percibe cómo se fluctúa la convivencia en el Colegio Militar Leoncio Prado para adoptar una postura heteróclita acerca de cómo se desenvolverá en ese lugar sin recibir ningún daño. Ese rasgo auténtico no será estático, pues también se le anulará esa conducta privilegiada al ser derrotado y agredido por toda su sección. De ese corolario, se obtiene lo que Van Soest denomina como violencia estructural y cultural (García y Ramos, 2000: 34-35). Esa atribución es pertinente debido a que se acota cómo una acción provoca una transgresión a lo que anteriormente se había establecido. Es más, esa revelación suscita que conmute la secuencia de lo cotidiano en su institución. Desde ese momento, el Jaguar ya no tendrá el mismo valor.

Sexto, las acciones serán reconocibles según su transitividad o su intransitividad (Doležel, I999: 9I). Las primeras se manifiestan cuando el agente origina cambios en el mundo al sustituir objetos, transformarlos o variar su forma. Estas se desarrollan con asimetría, ya que la afección no perturba a la persona con las mismas reacciones. Eso se evidencia en la mayoría de estudiantes. Ellos se percatan de que el universo castrense se mantendrá. El maltrato que sufran al ingresar no alterará en nada su conducta. Persistirán en las prácticas de la violencia, y no buscarán un pretexto para claudicar. Entretanto, las acciones intransitivas son generadas cuando el agente que interviene resulta transmutado por movimientos corporales, ya sea por la modificación de sus estados o sus propiedades. Eso se corrobora cuando el Poeta se comporta con más determinación por la muerte del Esclavo. Ese homicidio lo dañará a él particularmente, puesto que no adopta un efecto similar en el resto de los cadetes.

Con esta taxonomía fluctuada, Doležel (I999: I47-I48) cree que es conveniente especificar que las condiciones a las que se somete una acción son múltiples, merced a que la heterogeneidad de las relaciones multipersonales en el mundo. Esa premisa confirma que cada persona se integra a una red de interacciones interpersonales, de modo que el ser existe en tanto su vínculo dinámico con el otro. Ese procedimiento será notorio por el desempeño y las pretensiones que confluyen, así como la correspondencia que se 
exhibe en la forma de vivir la acción y el espacio de la conciencia en el que se desenvuelve y se ubica su valor estético. Verbigracia, en un relato, la función de un personaje es destacable si esta se evidencia por medio de una oración. Por ende, su participación revela una estimación como unidad de sentido que es. Asimismo, Paul Ricoeur (I998: 32I) considera que ese reconocimiento es medular en cuanto que se trata de un sujeto gramatical que cuenta con un predicado de acción. Para constatarlo, será necesario que se cumpla la fórmula narrativa " $\mathrm{X}$ hace $\mathrm{R}$ ”. Lo que realice tendrá que describir a las personas y los objetos, así como facilitar al lector el desentrañamiento de sus rasgos físicos o psicológicos, que pueden ser explícitos en el discurso. Esa configuración se aprecia en el siguiente diálogo: “Por qué me hablas en ese tono? -dijo Teresa-. Dime la verdad, Alberto. ¿Por qué estás enojado conmigo? ¿Te han dicho algo de mí?” (Vargas Llosa, 2OI2: 3I5). De allí, se ausculta la identidad de dos personajes por la mención de sus nombres, aunque también se detectan las emociones exorbitantes por las que atraviesan: el temor y el enfado. Algo similar se muestra en el siguiente ejemplo: “Alberto gritó: 'Si alguien hace una broma más, le saco la puta que lo parió”” (Vargas Llosa, 2OI2: 296). La diferencia con el caso anterior es que aquí no se manifiestan los estados de ánimo, pero puede inferirse la molestia con la que se distingue el personaje por expresarse con furia y recurrir a un lenguaje grosero.

Para terminar, se colige que la acción y el personaje están íntimamente arraigados. Pueden ser felices o denigrantes. Esa decisión dependerá de su proceder (Aristóteles, 200o: 79). Tendrá que existir una correlación que no se altere con el decurso del tiempo, al menos que esté bien justificada. La unidad del relato requerirá que esta entidad sea consecuente con su personalidad. Su composición deberá ser verosímil y tendrá que provocar en el lector la capacidad para poder deducir sus comportamientos o generarles alguna emoción. No se le atribuirá un desempeño que no vaya de acuerdo con su modo de ser. Eso explica por qué el Jaguar no se dejará jamás insultar por el Esclavo y aun ser agredido por él. Ese mismo procedimiento ocurre con el desarrollo de la trama. Se escoge un personaje funcional. Se tiene un cuidado minucioso al caracterizarlo. Se le designa una historia y se facilita toda la información necesaria para que esta se fluctúe con continuidad, pese a que se puedan presentar obstáculos. Por ejemplo, una vez que muere Ricardo Arana, lo que importa más en la narración es concatenar las historias que sirvan para reconstruir los hechos y hallar al culpable del homicidio. Una intervención del Boa no será efectiva en ese momento ni el pasado de alguno de los protagonistas.

\section{Conclusiones}

Con este artículo, se comprendió cómo se incluyó la noción de conservadurismo en la obra literaria de Mario Vargas Llosa. Su extrapolación fue indispensable para reconocer la posición desbridada del autor y su propósito de querer mostrar la realidad de la sociedad latinoamericana desde su sometimiento involuntario a ideologías concomitan- 
tes del militarismo dictatorial. Para ampliar el contenido de esta premisa, argumentaré con sincretismo los tres abordajes que oscilaron en este estudio.

La primera parte permitió ubicar una explicación extratextual en torno a la postura conservadora del novelista. Se dilucidó que uno de los rasgos de esa afiliación política consistía en proyectar la realidad desde una perspectiva neutral. La volición de esa representación se basó en exhibir el periodo tal como era, para que el lector formara un juicio en su ipseidad. Esa labor se haría con mucha dedicación, ya que el trabajo que se efectuó con las técnicas para plasmar ese universo era meritorio. Sin embargo, eso no significaba que la afinidad del escritor peruano por algún criterio se hiciera explícita. La justificación para demostrar eso fue el desarrollo del contexto que se arguyó. Luego del tratamiento expuesto, se entendió por qué el país desautorizó el dogma castrense y cualquier manifestación violenta. La concepción de progreso e innovación no se corroboraban en la práctica; más bien, ese tipo de adoctrinamiento revelaba que se estaba incurriendo en situaciones amorales. Asimismo, estas deducciones se pudieron cotejar en investigaciones hechas por la crítica literaria, de las cuales se halló el empecinamiento por comprobar la presencia de antivalores en la formación militar que se patentizaba en los personajes de La ciudady los perros.

Acerca del apartado que abordó la definición de la violencia, se pudo constatar que Mario Vargas Llosa sirvió como canal para proferir las deficiencias por las que atravesaba una sociedad distinguida por ser gobernada por una enseñanza castrense. Eso se consiguió por la epifanía de su postura conservadora y su pretensión por querer abarcar la realidad con un ímpetu totalizante. Para justificar eso, fue lisonjero construir un paradigma de la violencia y postular una taxonomía que se vinculara con la pragmática que expresaba la obra literaria. Una idea perenne desde la contextualización y la interpretación fue que existía un interés por respaldar el adiestramiento militarizado y agresivo a los alumnos por la creencia de que sería de utilidad para convertirlos en verdaderos hombres. Con las dos modalidades de V. P. Shupilov, se pudieron localizar talantes que argumentaban que no se obtenía nada provechoso a partir de este tipo de adoctrinamientos. Más bien, los daños que se ocasionaban eran muy nocivos e irrevocables. Y las consecuencias eran más intrincadas si se percibían malas formaciones en la niñez.

Con la última sección de esta pesquisa, se comprobó lo neurálgico que era auscultar la correspondencia entre acción y personaje para cerciorarse de las identidades singularizadas y su respectiva evolución humana. Todo ello adoptaría una dinámica peculiar desde la inclusión y el tratamiento de la violencia. Eso se demostró con la epistemología de Vladimir Propp, que consistió en la segmentación de las secuencias narrativas de los actantes, así como fue de importancia la nomenclatura de las acciones que desarrolló Lubomír Doležel. Esa división permitió intuir la realidad de manera fidedigna y el panorama que se comprendía desde una instrucción militarizada; en rigor, fue notoria la cosmovisión conservadora del autor al haber configurado una sociedad con sus problemas inmanentes y sin encontrar alguna solución. 


\section{Bibliografía}

- Arendt, H. (2008). Sobre la violencia. Madrid: Alianza Editorial.

- Aristóteles (200o). Poética (Salvador Mas, trad.). Madrid: Biblioteca Nueva.

- Beristáin, H. (1997). Análisis estructural del relato literario. Ciudad de México: Universidad Nacional Autónoma de México.

- Boldori de Baldussi, R. (I974). Vargas Llosa, un narrador y sus demonios. Buenos Aires: F. García Cambeiro.

- Brooks, S. (2005). La ciudad y los perros. Journal of Latin American Geography, 4 (2), I23-I25.

- Caballero, C. (2OII). Teoría de la novela y pensamiento político en la obra de Mario Vargas Llosa (tesis de maestría). Lima: Pontificia Universidad Católica del Perú.

- Delgado Del Aguila, J. M. (20I7). Protagonismo violento y modos de representación en La ciudad y los perros (I963) (tesis de licenciatura). Lima: Universidad Nacional Mayor de San Marco.

- Delgado Del Aguila, J. M. (20r9). Tipos de violencia en La ciudad y los perros (I963) de Mario Vargas Llosa. Estudios críticos tras su lectura. Alabe 2o. DOI: http://dx.doi. org/IO.I5645/Alabe2OI9.20.

- Doležel, L. (r999). Heterocósmica. Ficción y mundos posibles (Félix Rodríguez, trad.). Madrid: Arco/Libros.

- Domenach, J.-M.; Joxe, A.; Galtung, J.; et al. (I98I). La violencia y sus causas. París: Editorial de la Unesco.

- Elías, N. (1987). El proceso de la civilización. Investigaciones sociogenéticas y psicogenéticas (Ramón García Cotarelo, trad.). Madrid: Fondo de Cultura Económica.

- Espejel Mena, J. (20I6). Liberalismo, conservadurismo y administración pública. TlaMelaua. Revista de Ciencias Sociales, IO (I4), 22-47.

- Fontanille, J. (200I). Semiótica del discurso (Óscar Quezada Macchiavello, trad.). Lima: Universidad de Lima, Fondo de Desarrollo Editorial.

- Gálvez Acero, M. (1992). La novela hispanoamericana contemporánea. Madrid: Taurus. 
- García, S. y Ramos, L. (200o). Medios de comunicación y violencia. Ciudad de México: Instituto Mexicano de Psiquiatría, Fondo de Cultura Económica.

- Gómez Alonso, M. (2009). Los principios del conservadurismo político. Opinión Jurídica, 8 (I6), 63-79.

- Gorriti, G. (I99I). Sendero. Historia de la Guerra Milenaria en el Perú. I. Lima: Apoyo.

- Hernández Granda, E. (2OOI). Agresividad y relación entre iguales en el contexto de la enseñanza primaria. Estudio piloto. Asturias, España, Trabajo de investigación. Programa de Doctorado: “Cooperación, Desarrollo Social y Democracia”. Universidad de Oviedo.

- Kristal, E. (2012). Refundiciones literarias y biográficas en La ciudad y los perros. En Vargas Llosa, Mario, La ciudad y los perros. Edición conmemorativa del cincuentenario (pp. 539-558). Italia: Alfaguara, Real Academia Española.

- Lacan, J. (1998). El seminario. Libro 5. Las formaciones del inconsciente (Jacques-Alain Miller, comp.). Buenos Aires: Paidós.

- Luchting, W. (1976). Mario Vargas Llosa, desarticulador de realidades. Bogotá: Plaza \& Janes.

- Magráns, R. (i994). Anti-Totalitarism in Animal Farm and Time of the Hero. En Hernández de López, Ana María (ed.), Mario Vargas Llosa: Opera Omnia (pp. 393-40o). Madrid: Pliegos.

- Magnarelli, S. (i976). The Time of the Hero: Liberty Enslaved. Latin American Literary Review, IV (8), 35-45.

- Marco, J. M. (2005). Conservadores, liberales y neoconservadores. Fundamentos morales de una sociedad libre. Cuadernos de Pensamiento Político, (8), I29-I40.

- Martín, J. L. (1979). La narrativa de Vargas Llosa; acercamiento estilístico. Madrid: Gredos.

- Oviedo, J. M. (I982). Mario Vargas Llosa: la invención de una realidad. Barcelona: Seix Barral.

- Propp, V y Mélétinski, E. (I98I). Morfología del cuento, Las transformaciones de los cuentos maravillosos y El estudio estructural y tipológico del cuento (Lourdes Ortiz, trad.). Madrid: Fundamentos (original publicado en I928).

- Ricoeur, P. (1998). Tiempo y narración. Configuración del tiempo en el relato histórico. Tomo I. Madrid: Siglo Veintiuno Editores. 
- Rubio, M., Mac Gregor, F. y Vega, R. (1990). Marco teórico y conclusiones de la investigación sobre violencia estructural (I. ${ }^{\mathrm{a}}$ ed.). Lima: Asociación Peruana de Estudios e Investigación para la Paz.

- Ruiz Carbonell, R. (2002). La violencia familiar y los derechos humanos. Ciudad de México: Comisión Nacional de los Derechos Humanos.

- Salazar Jaque, B. (2005). La violencia como temática en La ciudad y los perros de Mario Vargas Llosa (tesis de licenciatura). Chile: Universidad de Chile.

- Schweizer, R. (I994). Autoritarismo y falsa conciencia en La ciudad y los perros y Pantaleón y las visitadoras. En Hernández, Ana María (coord.), Mario Vargas Llosa: Opera Omnia (pp. 297-304). Madrid: Pliegos.

- Shaw, D. (1999). Nueva narrativa hispanoamericana. Boom. Posboom. Posmodernismo (6. ${ }^{\text {a }}$ ed.). Madrid: Cátedra.

- Vargas Llosa, M. (2OI2). La ciudad y los perros. Italia: Alfaguara, Real Academia Española (original publicado en I963).

- Vilela Galván, S. (2003). El cadete Vargas Llosa: la historia oculta tras "La ciudad y los perros". Santiago de Chile: Planeta.

- Von Beyme, K. (1985). El conservadurismo. Revista de Estudios Políticos, (43), 7-44. 